\title{
Denoting Concepts, Reference, and the Logic of Names, Classes as Many, Groups, and Plurals
}

\author{
Nino B. Cocchiarella
}

\begin{abstract}
Bertrand Russell introduced several novel ideas in his 1903 Principles of Mathematics that he later gave up and never went back to in his subsequent work. Two of these are the related notions of denoting concepts and classes as many. In this paper we reconstruct each of these notions in the framework of conceptual realism and connect them through a logic of names that encompasses both proper and common names, and among the latter complex as well as simple common names. Names, proper or common, and simple or complex, occur as parts of quantifier phrases, which in conceptual realism stand for referential concepts, i.e., cognitive capacities that inform our speech and mental acts with a referential nature and account for the intentionality, or directedness, of those acts. In Russell's theory, quantifier phrases express denoting concepts (which do not include proper names). In conceptual realism, names, as well as predicates, can be nominalized and allowed to occur as "singular terms", i.e., as arguments of predicates. Occurring as a singular term, a name denotes, if it denotes at all, a class as many, where, as in Russell's theory, a class as many of one object is identical with that one object, and a class as many of more than one object is a plurality, i.e., a plural object that we call a group. Also, as in Russell's theory, there is no empty class as many. When nominalized, proper names function as "singular terms" just the way they do in so-called free logic. Leśniewski's ontology, which is also called a logic of names can be completely interpreted within this conceptualist framework, and the well-known oddities of Leśniewski's system are shown not to be odd at all when his system is so interpreted. Finally, we show how the pluralities, or groups, of the logic of classes as many can be used as the semantic basis of plural reference and predication. We explain in this way Russell's "fundamental doctrine upon which all rests," i.e., "the doctrine that the subject of a proposition may be plural, and that such plural subjects are what is meant by classes [as many] which have more than one term" ([PoM], p. 517).
\end{abstract}

Bertrand Russell introduced several novel ideas in his 1903 Principles of Mathematics [PoM] that he later gave up and never went back to in his subsequent work. Two of these are the related notions of denoting concepts and classes as many. Russell explicitly rejected denoting concepts in his 1905 paper, "On Denoting". Although his reasons for doing so are still a matter of 
some debate, they depend in part on his assumption that all concepts, including denoting concepts, are objects and can be denoted as such. ${ }^{1}$ Classes of any kind were later eliminated as part of Russell's "no-classes" doctrine, according to which all mention of classes was to be contextually analyzed in terms of reference to either propositions, as in Russell's 1905 substitution theory, or propositional functions as in Principia Mathematica [PM]. The problem with classes, as Russell and Whitehead described it in [PM], is that

"if there is such an object as a class, it must be in some sense one object. Yet it is only of classes that many can be predicated. Hence, if we admit classes as objects, we must suppose that the same object can be both one and many, which seems impossible" (p. 72).

Both notions are worthy of reconsideration, however, even if only in a somewhat different, alternative form in a conceptualist framework that Russell did not himself adopt. In such a framework, which we will briefly describe here,

Russell's assumption that all concepts are objects will be rejected in favor of a conceptualist counterpart to Frege's notion of unsaturatedness, and we will reconsider the idea of a class as many somehow being both one and many.

\section{Denoting Concepts and Classes as Many}

According to Russell, a "concept denotes when, if it occurs in a proposition [as an objective truth or falsehood], the proposition is not about the concept, but about a term connected in a certain peculiar way with the concept" ([PoM], p. 53). In particular, denoting concepts occur in propositions the way that quantifier phrases occur in the sentences that express those propositions. Denoting concepts, in other words, are what the quantifier phrases of natural language express or stand for. Russell described only the quantifier phrases based on the six determiners 'all', 'every', 'any', 'a', 'some', and 'the', though there is no reason why phrases based on other determiners, such as 'few', 'most', 'several', etc., could not also be included. ${ }^{2}$ A quantifier phrase results when a determiner is applied to a common count noun, which, according to Russell, expressed a class-concept. Russell also called a quantifier phrase a denoting phrase. Thus, a "denoting phrase ... consists always of a class-concept [word or phrase] preceded by one of the above six words or some synonym of one of them" (ibid., p. 56). Putting the determiner 'the' aside and taking man as an example of a classconcept, Russell claimed that there is "a definite something, different in each of the five cases, which must in a sense, be an object, but is characterized as a set of terms combined in a certain way, which something is denoted by all men, every man, any man, a man, or some man; and it is with this very paradoxical object that propositions are concerned that the corresponding concept is used

\footnotetext{
${ }^{1}$ This occurs in his attempt to denote the meaning of a denoting phrase, which is the denoting concept expressed by that phrase. See Russell's [OD], p. 50 .

${ }^{2} \mathrm{See}[\mathrm{PoM}]$, p. 55 . We will not ourselves be concerned with these other types of determiners in this paper.
} 
as denoting" (ibid., p. 62.). ${ }^{3}$ The object in the case of all men is the class as many of men, which, according to Russell, is also denoted by 'men', the simple plural of 'man', and which Russell takes as a synonym of 'all men' (ibid., p. 67). The other objects are more problematic, or "paradoxical", as Russell says.

The object denoted by 'any man', for example, is said to be a "variable conjunction" of individuals, whereas the object denoted by 'a man' is a "variable disjunction" of individuals, as opposed to the object denoted by 'some man', which Russell calls a "constant conjunction" of individuals. These are indeed strange kinds of objects, and we will not attempt to make sense of them here. But in giving these up Russell also gave up the notion of a class as many, which, unlike the others can be formally developed in a way that provides a semantic basis for plural reference and predication, just as Russell originally proposed. ${ }^{4}$ Russell's reason for giving up the notion was that "even if there were such an object as 'all men', it is plain that it is not this object to which we attribute mortality when we say 'all men are mortal'" ([1908], p. 70). This objection, however, as we will later see, confuses mortality as represented by the verb phrase 'is mortal' in the singular with mortality as represented by the plural verb phrase 'are mortal'.

There is a notion of a combination, or conjunction, of terms that Russell uses that we will attempt to reconstruct, however. In particular, according to Russell, a finite class as many is "a numerical conjunction of terms" ([PoM], p. 67). "Thus Brown and Jones are a class, and Brown singly is a class. This kind of combination," according to Russell, "is the extensional genesis of classes" (ibid.). A class as many that is specified by such a combination, or enumeration, of terms is what Russell also called a collection; that is, a collection is "what is conveyed by ' $A$ and $B$ ' or ' $A$ and $B$ and $C$ ', or any other enumeration of definite terms" (ibid., p. 69). The word 'and', according to Russell, represents "a fundamental way of combining terms, and that just this way of combination is essential if anything is to result of which a number other than 1 can be asserted" (ibid.). There is "a grammatical difficulty," Russell observes, that "must be pointed out and allowed for," however, namely that "[a] collection, grammatically, is singular, whereas $A$ and $B, A$ and $B$ and $C$, etc. are essentially plural" (ibid.). A collection, in other words - i.e., a plurality, or what we will call a group - can in some contexts be spoken of in the singular even though what we are speaking of is a plural object.

"The fundamental doctrine upon which all rests," according to the Russell of $[\mathrm{PoM}]$, at least as far as the reduction of mathematics to logic is concerned, "is the doctrine that the subject of a proposition may be plural, and that such plural subjects are what is meant by classes [as many] which have more than

\footnotetext{
${ }^{3}$ One might well surmise that the problem of improper definite descriptions, i.e., the lack of denotata for the denoting concepts expressed by such descriptions, was why Russell put aside the determiner 'the' in this context. Had he available the "free logic" approach later developed, as we do here in our conceptualist alternative, he would have been able to handle this situation as well.

${ }^{4}$ See Cocchiarella [LCM] for a formal development and proof of consistency of a logic of classes as many, as well as an application of that logic to the semantics of plurals.
} 
one term" (ibid., p. 517).

\section{Reference and Predication in Conceptual Re- alism}

In conceptual realism, our primary concern is with reference and predication in speech and mental acts and not, as in $[\mathrm{PoM}]$, with denoting concepts as components of propositions as abstract entities. To be sure, there are propositions as the intensional contents of our speech and mental acts in conceptual realism, but these are derivative from, and dependent on, the functional role of those acts in thought and communication. In particular, as intensional objects, propositions are evolutionary products of language and culture, derived through a process of reflective abstraction corresponding to the linguistic practice of nominalization. ${ }^{5}$

There are other differences as well between Russell's denoting concepts and the referential concepts of conceptualism; but there are also some similarities. One important similarity is that, as in Russell's 1903 theory - and the medieval supposition theory of Ockham and others - conceptual realism gives a unified account of both singular and general reference - and of plural reference as well, which, apparently, the medieval theory did not do. ${ }^{6}$ Most theories of reference in the 20th Century have been theories only of singular reference, as in the use of proper names and definite descriptions. In Reference and Generality, [R\&G], Peter Geach argued against the whole idea of general reference and criticized both Russell's theory and the medieval theory in particular. In "Reference in Conceptual Realism", [RCR], we showed that Geach's arguments fail in conceptual realism, and in "A Logical Reconstruction of Medieval Terminist Logic in Conceptual Realism", [LRML], we showed that they fail against the medieval theory as well if the latter is understood as reconstructed there. If Russell's theory were reinterpreted as a variant of conceptual realism rather than as a form of logical realism, then they would fail there as well.

The main similarity between denoting concepts and referential concepts is that both are what quantifier phrases express or stand for, where, by a quantifier phrase we mean a quantifier, such as $\forall$ or $\exists$ (or any operator representing a determiner), indexed by a variable, and attached to a common name, i.e., the kind of name that Russell took to express a class-concept. In conceptualism, however, common names can be complex as well as simple and are part of a more general category that includes proper names as well. ${ }^{7}$ Another similarity is that there is a difference in both theories between a plural (collective) reference to all men, as in an assertion of

All men are mortal.

\footnotetext{
${ }^{5}$ For a discussion of this reflexive abstraction through nominalization, see Cocchiarella [CRLF].

${ }^{6}$ Other than in Cocchiarella [LCM], plural reference was not an issue in previous papers on conceptual realism but is a recent development of this framework.

${ }^{7}$ Though there is no reason to think that he would have excluded them, Russell does not mention complex class-names in $[\mathrm{PoM}]$.
} 
and a general (distributive) reference to every man, as in an assertion of

Every man is mortal.

This is because in both theories the quantifier phrases 'All men' and 'Every man' denote, or stand for, respectively, different denoting or referential concepts (and in conceptualism the verb phrases stand for different predicable concepts as well). Thus in Russell's theory, the propositions expressed in these assertions are different because they contain different denoting concepts - though, apparently, Russell also took these different propositions to be logically equivalent. In conceptualism, however, although 'Every man is mortal' implies 'All men are mortal', the converse, as we will later see, is not also true, which means that their truth conditions are different, and hence that the propositions expressed are not only different but not logically equivalent as well.

In Russell's theory, again because of a difference in denoting concepts, both of these propositions are also different from that expressed by

Everything is such that if it is a man, then it is mortal.

though, again, Russell seemed to think that this proposition is logically equivalent to the others. In conceptualism, because of a difference in referential and predicable concepts, the cognitive structure of an assertion of (3) is different from that of an assertion of (2), but the two do have the same truth conditions and hence express the same proposition; both, however, differ in cognitive structure and truth conditions from an assertion of (1) if we assume, as we do here, that 'all men' is the dual of 'some men' as used in a plural reference.

That we do not make a category distinction between proper names and common names is a noteworthy difference between our conceptualist theory of referential concepts and Russell's realist theory of denoting concepts. Proper names are of course paradigms of expressions that are used to refer, but what this means in conceptualism, as we note below, is that such a use is represented by a quantifier phrase. That is not how Russell understood the use of a proper name of course. But then Russell also did not distinguish the use of a proper name with, as opposed to without, existential presupposition. Such a distinction is fundamental if our goal is to represent the cognitive structure, and in particular the referential and predicable aspects, of our speech and mental acts, as it is in conceptualism. Thus, for example, an assertion of 'Socrates is wise', where the name 'Socrates' is used with existential presupposition, is represented in our conceptualist theory by

$$
\text { ( } \exists x \text { Socrates }) W i s e(x),
$$

whereas an assertion of the same sentence, but without existential presupposition, is symbolized as

$$
(\forall x \text { Socrates }) \text { Wise }(x) .
$$

The fact that a proper name, unlike most common names, is used to refer to at most one thing is stipulated by a meaning postulate and not by a category 
distinction between proper names and common names, or what Russell called class-concepts. ${ }^{8}$

Referential and predicable concepts in the kind of conceptualism we have in mind here are the intersubjectively realizable cognitive capacities that underlie our rule-following use of noun and verb phrases in natural language. That is, just as noun phrases and verb phrases are complementary, mutually saturating linguistic structures of our basic speech acts when noun phrases are used as grammatical subjects, so too, in conceptual realism, referential and predicable concepts are complementary, mutually saturating cognitive structures that underlie those acts. As cognitive structures, neither kind of concept is a mental image or object of any kind; rather, both are unsaturated cognitive capacities that when jointly exercised inform a speech or mental act with a predicable and referential nature, respectively. ${ }^{9}$ This is not the Fregean notion of unsaturatedness - which was a characteristic of functions of all types - though there is a similarity in that being unsaturated precludes being an object. Moreover, although predicable and referential concepts are not objects, their joint exercise and mutual saturation in a speech or mental act does result in an object, namely a speech or mental event, but not a truth value or proposition as Frege or Russell would have it. It is noteworthy, moreover, that as cognitive capacities, referential and predicable concepts can be exercised by different people at the same time as well as by the same person at different times, which is why, following a medieval tradition, we sometimes describe them as intelligible universals, though universals of different and complementary types.

\section{Cognitive Structure and Logical Form}

One of the purposes of logical syntax in conceptual realism is to represent not only the truth conditions of our speech and mental acts, and the logical consequences of those truth conditions, but also the cognitive structures of those acts. That is why predicable concepts, both simple and complex, are represented by predicate constants and $\lambda$-abstracts, and referential concepts are represented by quantifier phrases, where the latter consist of a variable-binding operatorsuch as the universal or existential quantifier, or operators representing other determiners of natural language - indexed by a variable and attached to a name, either proper or common and simple or complex. Thus, on this account, the logical form representing the cognitive structure of an assertion of 'Every man is mortal' is represented by

$$
(\forall x M a n) \operatorname{Mortal}(x),
$$

or, using a $\lambda$-abstract, by

$$
(\forall x M a n)[\lambda x M \operatorname{Mrtal}(x)](x) .
$$

\footnotetext{
${ }^{8}$ We restrict ourselves here to common names that are common count nouns. How mass nouns are to be represented is an issue we do not deal with in this paper.

${ }^{9}$ All speech acts are mental acts, but not all mental acts are speech acts. The same cognitive capacities that underlie our speech acts underlie our mental acts.
} 
The quantifier phrase $(\forall x M a n)$ stands for the referential concept being exercised in that assertion, and the predicates $\operatorname{Mortal}(x)$ and $[\lambda x \operatorname{Mortal}(x)]$ stand for the predicable concept that is also being exercised in that assertion. ${ }^{10}$

An assertion of (2), 'Everyman is mortal', as already noted, has the same truth conditions as an assertion of (3), 'Everything is such that if it is a man, then it is mortal'. The fact that the two general, distributive forms are equivalent is a consequence of the following (export-import) axiom schema:

$$
(\forall x A) \varphi \leftrightarrow(\forall x)[(\exists y A)(x=y) \rightarrow \varphi], \quad \text { (Exp-Imp1) }
$$

where $A$ is a variable of the primitive category of names, both proper and common, and simple or complex, and where $(\forall x)$ is read as (or is taken as abbreviating) ( $\forall x$ Thing $)$ or $(\forall x$ Object). Speech acts that have the same truth conditions of course do not necessarily have the same cognitive structure, and, at least with respect to the referential concepts being exercised, these two assertions in fact do not. Similarly, an assertion of 'Socrates is wise', where 'Socrates' is used with existential presupposition, has the same truth conditions, but different cognitive structure, as an assertion of 'Something (is) identical with Socrates (and) is wise'. That the two have the same truth conditions is a consequence of the related (export-import) schema,

$$
(\exists x A) \varphi \leftrightarrow(\exists x)[(\exists y A)(x=y) \wedge \varphi] . \quad \text { (Exp-Imp2) }
$$

Here, we read the quantifier expression ' $(\exists x)$ ' as short for ' $(\exists x T h i n g)$ ', or, equivalently, '( $\exists x$ Object $)$ '. ${ }^{11}$

A similar observation about this difference between truth conditions and cognitive structure, at least as based on the referential and predicable concepts being exercised, applies to the use of complex common names. Thus, an assertion of

Everyone who is civilized loves classical music.

has the same truth conditions as an assertion of

Everyone (person) is such that if $\mathrm{s} /$ he is civilized, then $\mathrm{s} /$ he loves classical music.

\footnotetext{
${ }^{10} \mathrm{~A}$ predicate constant or variable and its corresponding $\lambda$-abstract are assumed to stand for the same concept. Thus, where $F$ is an $n$-place predicate constant or variable, the following is a theorem of the general framework,

$$
F=\left[\lambda x_{0} \ldots x_{n-1} F\left(x_{0}, \ldots x_{n-1}\right)\right] .
$$

${ }^{11}$ As we will see later, once the logic of classes as many is introduced, these expressions are also equivalent to:

$$
(\exists x)[\text { Socrates }=x \wedge W i s e(x)],
$$

and

$$
(\forall x)[\text { Socrates }=x \rightarrow \text { Wise }(x)],
$$

respectively, which are the more standard way of expressing the different uses of a proper name in a logic free of existential presuppositions.
} 
even though the two have different cognitive structures. In the logical syntax of conceptual realism, a defining relative clause, such as 'who is civilized', is represented by attaching a '/' to a common name followed by a formula, the result of which is a complex common name. Thus, on this account, (4), 'Everyone (person) who is civilized', is symbolized as

$$
(\forall x \text { Person/ Ci vilized }(x))
$$

where 'person who is civilized' is a complex common name. The fact that these two assertions (with different cognitive structures) have the same truth conditions is a consequence in our conceptualist framework of the following (export-import) axiom schema:

$$
(\forall x A / \varphi) \psi \leftrightarrow(\forall x A)(\varphi \rightarrow \psi),
$$

(Exp-Imp3)

which, as in these examples, stipulates that the one assertion is true if, and only if, the other is. The related schema regarding the truth conditions for 'Someone who is civilized loves classical music' is:

$$
(\exists x A / \varphi) \psi \leftrightarrow(\exists x A)(\varphi \wedge \psi) .
$$

Defining relative clauses that are iterated, as in 'Every professor who is male, bald and middle-aged is having a mid-life crisis' are covered by the same schemas. This is because we associate the iterated occurrences of '/' to the left, so that

$$
(\forall x A / \varphi / \chi / \xi) \psi
$$

is then seen to be equivalent to

$$
(\forall x A / \varphi)(\chi \rightarrow[\xi \rightarrow \psi]),
$$

which in turn is equivalent to

$$
(\forall x A)(\varphi \rightarrow(\chi \rightarrow[\xi \rightarrow \psi])),
$$

and more simply to

$$
(\forall x A)(\varphi \wedge \chi \wedge \xi \rightarrow \psi) .
$$

Also, note that $(\forall x / F(x)) G(x)$, which is read as 'Everything that is $F$ is $G$ ', is then equivalent to $(\forall x)[F(x) \rightarrow G(x)]$, which is read as 'Everything is such that if it is $F$, then it is $G^{\prime}{ }^{12}$

Though it might be a point of some contention, we also take an assertion of 'Every civilized person loves classical music' to have the same cognitive structure, and not just the same truth conditions, as an assertion of 'Everyone (person) who is civilized loves classical music'. In other words, most, though not all, prenominal modifiers (attributive adjectives) really amount to defining relative clauses on a common name. Thus a civilized person is a person who is civilized

\footnotetext{
${ }^{12}$ See Cocchiarella, [LCM], $\S 2$, for a detailed description for what is there called the simple logic of names.
} 
and a red car is a car that is red, etc. Some problematic cases, such as 'alleged thief', or 'big mouse', can be expressed in terms of a relative clause, as 'person who is alleged to be a thief' and 'mouse that is big for a mouse' (or 'mouse that is bigger than most mice', which is sometime challenged as inadequate). The prenominals 'fake', as in 'fake diamond', 'dead' as in 'dead man', and 'pseudo-' as in 'pseudo-intellectual' are probably not analyzable this way but must instead be taken as common names themselves. ${ }^{13}$ Meaning postulates would then stipulate that a fake diamond is not a diamond, that a dead man is not a man (anymore), and that a pseudo-intellectual is not an intellectual.

Finally, although Russell did not say what denoting concept was expressed by the definite article, it is noteworthy that in conceptualism this kind of singular reference has essentially the same truth conditions that Russell later gave to definite descriptions, at least when the use of the definite description is with, as opposed to without, existential presupposition. Thus, in conceptualism an assertion of the form

$$
\text { The } A \text { that is } F \text { is } G \text {, }
$$

where the referential concept expressed by 'The $A$ that is $F$ ' is used with existential presupposition, is symbolized as

$$
\left(\exists_{1} x A / F(x)\right) G(x) .
$$

Here, the definite description is represented by $\left(\exists_{1} x A / F(x)\right)$, where $\exists_{1}$ is a variable-binding operator (quantifier) representing the determiner 'the'. The fact that this assertion has the same truth conditions as the sentence, 'There is exactly one $A$ that is $F$ and it is $G$ ', is stipulated in the following axiom schema:

$$
\left(\exists_{1} x A / F(x)\right) G(x) \leftrightarrow(\exists x A / F(x))[(\forall y A / F(y))(y=x) \wedge G(x)] .
$$

When 'The $A$ that is $F$ ' is used without existential presupposition, we have the following schema:

$$
\left(\forall_{1} x A / F(x)\right) G(x) \leftrightarrow(\forall x A / F(x))[(\forall y A / F(y))(y=x) \rightarrow G(x)],
$$

which tells us that the assertion has the same truth conditions as 'If there is exactly one $A$ that is $F$, then it is $G^{\prime}$.

\section{Leśniewski's Logic of Names}

Stanislaw Leśniewski, who with Łukasiewicz was a founder of the Warsaw school of logic, was greatly influenced by Russell's paradox and Russell's subsequent development of the ramified theory of types. His own later system of logic consisted of several parts, one being a version of the simple theory of types, but which he called a theory of semantic categories; another, which was really a part

\footnotetext{
${ }^{13}$ It is not clear, e.g., that 'fake' is to be construed as a modifier of common names; otherwise, by iteration we would have such oddities as 'fake fake diamond' and 'fake fake fake diamond'. An alternative is to take 'fake diamond' as a basic common name itself.
} 
of his theory of types, was a quantified propositional logic with quantifiers over truth functions, which he called protothetic. A third was mereology, a theory of the relation between parts and wholes; and a fourth was his system of ontology, which was a logic of names that he placed at the base of his theory of types. ${ }^{14}$ The logic of names, it turns out, is strikingly similar to the conceptualist logic of names briefly described above - except, that is, for how the category of names figures in the logical forms of each theory. Nevertheless, despite this difference, Leśniewski's logic of names can be translated into, and in that sense completely interpreted within, our conceptualist logic of names, so that the translation of every theorem of Leśniewski's logic becomes a theorem of our conceptualist logic. ${ }^{15}$ Also, because our conceptualist logic of names is part of the fuller system of conceptual realism, which is equivalent to the simple theory of types, this means that Leśniewski's entire system, except perhaps for mereology, is completely interpretable within the framework of conceptual realism.

In Leśniewski's logic of names, as in our conceptualist logic, there is distinction between (1) shared or common names, such as 'man', 'horse', 'house', etc., and even the ultimate superordinate common name 'thing'; (2) unshared names, i.e., names that name just one thing, such as proper names; and (3) vacuous names, i.e., names that name nothing. ${ }^{16}$ The categorial difference, however, is that in Leśniewski's system names are of the same category as the variables of lowest type or order, which are usually called individual, or object, variables, and which means that they are legitimate substituends for those variables. In our conceptualist logic, as already noted, names form a separate category to which quantifiers are applied and that result in quantifier phrases when so applied.

Because of the way that names are represented in his logic, Leśniewski's system has seemed odd or quirky to many logicians and philosophers of logic. The one primitive of this logic, aside from logical constants, is the relation symbol ' $\varepsilon$ ' for singular inclusion, which is read as the copula 'is (a)', as in 'John is a teacher', where both 'John' and 'teacher' are names. ${ }^{17} \mathrm{With}$ ' $a$ ', ' $b$ ', 'c', etc., as individual constants or variables for names, the basic formula of the logic is ' $a \varepsilon b$ ', and though either shared, unshared, or vacuous names may occur in place of ' $a$ ' and ' $b$ ' in this formula, a statement of this form is taken to be true only if ' $a$ ' names exactly one thing and that thing is also named by ' $b$ ', though ' $b$ ' might name other things as well, as in our example of 'John is a teacher'. Identity is not a logical primitive of the system, as it in our conceptualist logic, but is defined instead as follows:

$$
a=b={ }_{d f} a \varepsilon b \wedge b \varepsilon a .
$$

That is, ' $a=b$ ' is true in Leśniewski's logic if, and only if, ' $a$ ' and ' $b$ ' are

\footnotetext{
${ }^{14}$ See Slupecki's [LC] for a description of the different parts of Leśniewski's system.

${ }^{15}$ See Cocchiarella's [CILO] for a detailed proof of this claim.

${ }^{16}$ See Lewjeski's [LO] for a detailed description of Leśniewski's logic of names.

${ }^{17}$ Apparently, it was Łukasiewicz who prompted Leśniewski to develop his logic of names when he expressed dissatisfaction with the way G. Peano used ' $\in$ ' for the copula in set theory. Cp. p. 414 of Rickey's [SLL].
} 
unshared names that name the same thing. That seems like a plausible thesis, except that then, where ' $a$ ' is a shared or vacuous name, ' $a=a$ ' is false. In fact, because there are necessarily vacuous names, such as 'thing that is both square and and not square', the following is provable in Leśniewski's logic:

$$
(\exists a)(a \neq a)
$$

which does not seem like a plausible thesis. Another valid thesis is:

$$
\varphi(c / a) \rightarrow(\exists a) \varphi(a),
$$

which seems counter-intuitive when ' $c$ ' is a vacuous name. Of course, maybe the quantifiers are not to be interpreted referentially but substitutionally as Quine once suggested ([RR], p. 99). That, however, is not how Leśniewski seemed to understand his logic of names, which he also called ontology. ${ }^{18}$

It should also be noted that despite the similarity of Leśniewski's episilon symbol, ' $\varepsilon$ ', with the epsilon symbol, ' $\in$ ', of set theory, the two should not be confused. In particular, whereas the following:

$$
\begin{gathered}
a \varepsilon b \rightarrow a \varepsilon a, \\
a \varepsilon b \wedge b \varepsilon c \rightarrow a \varepsilon c,
\end{gathered}
$$

are both theorems of Leśniewski's system, both are invalid for membership in a set.

Now all of the oddities of Leśniewski's system are explained in our conceptualist logic once we locate the category of names as parts of quantifiers. Thus, correlating Leśniewski's name variables ' $a$ ', ' $b$ ', ' $c$ ', etc., with our conceptualist nominal variables ' $A$ ', ' $B$ ', ' $C$ ', etc., we can translate Leśniewski's basic formula ' $a \varepsilon b$ ' as:

$$
(\forall x A)(\forall y A)(x=y) \wedge(\exists x A)(\exists y B)(x=y),
$$

which translates ' $a \varepsilon b$ ' as saying that there is at most one $a$ and that some $a$ is (a) $b$, which is equivalent to saying that exactly one thing is (an) $a$ and that thing is (a) $b$, which, as already noted, is how Leśniewski understood ' $a \varepsilon b$ ' as singular inclusion. Note that the translation of Leśniewski's

$$
\varphi(c / a) \rightarrow(\exists a) \varphi(a)
$$

is:

$$
\varphi(C / A) \rightarrow(\exists A) \varphi(A),
$$

which is provable in our conceptualist logic (where $C$ is free for $A$ in $\varphi$ ). Also it easy to see that the translation of

$$
a \varepsilon b \rightarrow a \varepsilon a,
$$

namely,

$(\forall x A)(\forall y A)(x=y) \wedge(\exists x A)(\exists y B)(x=y) \rightarrow(\forall x A)(\forall y A)(x=y) \wedge(\exists x A)(\exists y A)(x=y)$,

\footnotetext{
${ }^{18}$ See, e.g., Lejewski [LO\} and Küng and Canty [SQLQ] for a discussion of this issue.
} 
which says that if exactly one thing is an $A$ and that thing is a $B$, then exactly one thing is an $A$ and that thing is an $A$. Similarly, the translation of

$$
a \varepsilon b \wedge b \varepsilon c \rightarrow a \varepsilon c,
$$

which we will avoid writing out in full here, says that if exactly one thing is an $A$ and that thing is a $B$ and that if exactly one thing is a $B$-which therefore is the one thing that is an $A$-then exactly one thing is $A$ and that thing is $C$, which is easily seen to be provable in our conceptualist logic.

In regard to the seemingly implausible thesis

$$
(\exists a)(a \neq a),
$$

let us note first that, by Leśniewski's definition of identity (and hence of nonidentity), $(a \neq a)$ is really short for $\neg(a \varepsilon a \wedge a \varepsilon a)$, which is equivalent to $\neg(a \in a)$. On our conceptualist interpretation, this formula translates into

$$
\neg[(\forall x A)(\forall y A)(x=y) \wedge(\exists x A)(\exists y A)(x=y)],
$$

which in effect says that it is not the case that exactly one thing is an $A$, a thesis that is provable in our conceptualist logic when $A$ is taken as a necessarily vacuous name, such as 'object that is not self-identical', which is symbolized as ' $/(x \neq x)$ ' (or more fully as 'Object $/(x \neq x)^{\prime}$ ). In other words, the translation of Leśniewski's thesis,

$$
(\exists a)(a \neq a),
$$

is equivalent in our conceptualist logic to

$$
(\exists A) \neg[(\forall x A)(\forall y A)(x=y) \wedge(\exists x A)(\exists y A)(x=y)],
$$

which is provable in this logic.

Note also that because $(a=b)$ in Leśniewski's logic means $(a \varepsilon b \wedge b \varepsilon a)$, then the translation of $(a=b)$ into our conceptualist logic becomes

$$
(\forall x A)(\forall y A)(x=y) \wedge(\exists x A)(\exists y B)(x=y) \wedge(\forall x B)(\forall y B)(x=y) \wedge(\exists x B)(\exists y A)(x=y),
$$

which in effect says that exactly one thing is $A$ and that thing is $B$, and that exactly one thing is $B$ and that thing is $A$, a statement that is true when $A$ and $B$ are proper names, or unshared common names, of the same thing, and false otherwise, which is exactly how Leśniewski understood the situation.

Finally, putting aside Leśniewski's definition of identity, it is noteworthy that even though ' $A=B$ ', unlike ' $x=y$ ', is not a well-formed formula of our conceptualist logic with identity as a primitive logical constant, nevertheless, it will be well-formed once we extend the framework to include a logic of classes as many in terms of the "nominalization" of names, i.e., once names are allowed to be transformed from expressions that occur only as parts of quantifier phrases to terms that can be substituted for object variables. And in that extended framework, as we will see, when $A$ and $B$ are proper names, or unshared common names, of the same thing, then $A=B$ will be true even independently of Leśniewski's definition of identity. 


\section{Nominalization and Logical Form in Concep- tual Realism}

The original core part of the logical framework of conceptual realism is a secondorder predicate logic that allows predicates to be nominalized and occur as abstract singular terms. The latter are understood not as denoting the predicable concepts that predicates stand for in their (pragmatic) role as predicates but the intensional contents of those concepts. ${ }^{19}$ This framework, as already noted, is equivalent to the theory of simple types, but, except for the grammatical distinction between predicates and their argument (or subject) positions, it is otherwise type-free in the traditional sense; i.e., there is no category distinction between different types of ( $n$-place) predicates (for each natural number $n){ }^{20}$ Of course, the distinction between names, proper or common and complex or simple, and predicates is a distinction between categories of expressions, but it is not a distinction between types of predicates, or types of singular terms, as in the traditional sense of type theory. Rather, it is a distinction based upon the different parts of speech in natural language.

This core framework contains not just a logic of nominalized predicates but of nominalized quantifier phrases as well. This second kind of nominalization is achieved first through a correlation of referential concepts-i.e., the concepts that quantifier phrases stand for-with certain corresponding predicable concepts, and then of the latter, through nominalization, with their intensional contents. In this way, we have a representation not only of the intensional contents of predicable concepts but of the intensional contents of referential concepts as well. In terms of cognitive structure, a nominalized quantifier phrase occurring, e.g., as the direct object of a transitive verb is not being actively used to refer but rather represents a deactivation of the referential concept the quantifier phrase stands for when it is used (as a grammatical subject) to refer to one or more things. For example, in 'John seeks a unicorn', the quantifier phrase 'a unicorn' that is the direct object of 'seeks' is not being used to refer to a unicorn; rather, the referential concept it stands for has been deactivated so that only its intensional content is involved in the truth conditions of the verb phrase 'seek a unicorn'. ${ }^{21}$ This deactivation is logically represented by a nominalization of the quantifier phrase as follows (where we assume 'John' is being used with existential presupposition):

$$
(\exists x J o h n)[\lambda x \operatorname{Seek}(x,[\exists y U \text { icorn }])](x) .
$$

\footnotetext{
${ }^{19} \mathrm{In}$ conceptualism, denotation is a semantic notion and is not the same as reference, which is a pragmatic notion. It is in the truth conditions of sentences, and especially of predicate expressions containing nominalized predicates as arguments, that the denotata of the latter play a role.

${ }^{20} \mathrm{Of}$ course there is a distinction between $n$-place and $m$-place predicates for $m \neq n$.

${ }^{21}$ This example is from Montague's [PTQ]. Montague's intensional logic does not involve the distinction between activated and deactivated referential concepts, however, but is a typetheoretical, logical realist framework in which intensional entities are higher-order objects instead.
} 
Here, as noted, the bracketed expression $[\exists y U$ nicorn] is really a nominalized (complex) predicate; i.e., by definition,

$$
[\exists y \text { Unicorn }]=[\lambda F(\exists y U \text { nicorn }) F(y)]
$$

where $[\lambda F(\exists y U$ nicorn $) F(y)]$ is short for $[\lambda z(\exists F)(z=F \wedge(\exists y U$ nicorn $) F(y))]$. The same nominalized (complex) predicate occurs in 'John finds a unicorn',

$$
(\exists x J o h n)[\lambda x \operatorname{Find}(x,[\exists y U \text { nicorn }])](x) .
$$

The difference between 'John seeks a unicorn' and 'John finds a unicorn' is not in their logical form, where the referential concept represented by 'a unicorn' has been deactivated in both, but in the fact that 'Seek', unlike 'Find', does not have a meaning postulate stipulating that it is extensional in its secondargument position. ${ }^{22}$ This difference between the activation of a referential concept and its deactivation, as in fiction as well as in intentional contexts, is another difference between the referential concepts of conceptual realism and the denoting concepts of Russell's theory. ${ }^{23}$ In Russell's theory, quantifier phrases express the same denoting concept and denote the same object whether used as grammatical subjects or as direct or indirect objects of discourse.

Now we will not be concerned with nominalizations of predicates and quantifier phrases in this paper but with a different type of nominalization altogether. ${ }^{24}$ Names, as we have said, whether proper or common and complex or simple, are used to refer when they occur in sentences as parts of quantifier phrases functioning as grammatical subjects. But names, both proper and common, as Geach has noted, can also be "used outside of the context of a sentence," namely, when they are used "in simple acts of naming," which are not assertions and do not involve the use of a name to refer ([R\&G], p. 52). "Nouns in the vocative case used in greetings, and again ejaculations like 'Wolf!' and 'Fire!' illustrate this independent use of names," according to Geach (ibid.). We also "get a very similar use of names when labels are stuck on things, e.g., 'poison' on a bottle or the name labels sometimes worn at conferences" (ibid.). This use, especially in the case of proper names and sortal common names, i.e., names that have identity criteria associated with their use, is conceptually prior to the referential use of names in sentences.

There are nonreferential uses of names in sentences as well, as when we speak of mankind, or humankind, by which we mean the totality, or entire group, of humans. ${ }^{25}$ Thus, we say that Socrates is a member of mankind, as well as

\footnotetext{
${ }^{22}$ That is, whereas for 'Find' we have the meaning postulate:

$$
[\lambda x \operatorname{Find}(x,[\mathcal{Q} y A])]=[\lambda x(\mathcal{Q} y A) \operatorname{Find}(x, y)],
$$

where $\mathcal{Q}$ is a quantifier, no such meaning postulate holds for 'Seek'-except perhaps for the phrase 'a certain', as in 'seek a certain unicorn'.

${ }^{23}$ The difference between an activated and a deactivated referential concept is the basis of our refutation in $[\mathrm{RCR}]$ of Geach's criticism of general reference in [ $\mathrm{R} \& \mathrm{G}]$.

${ }^{24}$ For a fuller description of the nominalization of quantifeir phrases and a defense of general reference, see Cocchiarella $[\mathrm{RCR}]$.

${ }^{25}$ See, e.g., Sellars [G\&E], p. 253.
} 
that Socrates is a man. Also, instead of 'mankind', we can use the plural of 'man' and say that Socrates is one among men. These are transformations of the name 'man' into a "singular term", i.e., an expression that can occur as an argument of predicates, and amount in effect to another type of nominalization. These kinds of nominalizations of 'man' and 'human' (as in 'humankind') are different, however, from the nominalization, or transformation, of the predicate adjective 'human' into an abstract singular term, 'humanity', or the gerundive phrase 'being human'; and they are similarly different from the transformation of 'man' into the infinitive and gerundive phrases 'to be a man' and 'being a man', which are represented in logical syntax by a nominalization of the (complex) predicate phrase $[\lambda x(\exists y M a n)(x=y)]$. In particular, whereas the latter are understood to denote an intensional object, the nominalized use of a name -i.e., the occurrence of its nominalization as an argument of a predicateis understood to denote the extension of the name, where, by the extension of a name, we mean a group or class as many. In other words, whereas a nominalzed occurrence of the predicate phrase 'is human' results in an abstract singular term that denotes the intension of the concept this predicate phrase stands for, a nominalized occurrence of the name 'man' (or 'human' when used as a name rather than an adjective) denotes the extension of the nominal concept the name stands for when used in a referential act; and such an extension is what we mean by a group or class as many. A class as many is the more general notion and a group is a class as many of two or more objects. Thus, by nominalizing a name, proper or common, we transform the name into a term, by which we mean an expression that can occur as an argument of predicates and that can be properly substituted for object (or so-called "individual") variables, and in particular a term that denotes, if it denotes at all, a class as many. ${ }^{26}$

\section{Classes as Many, Groups and Atoms}

There are three main features of classes as many as the denotata of nominalized occurrences of names. These are first that there is no empty class as many, i.e., that a name that names nothing has nothing as its extension. Secondly, the extension of a name that names just one thing is just that one thing. In other words, unlike a set, a class as many with just one member is identical with that one member. This feature shows that the extension of a proper name is just the object, if any, that the name denotes when it is nominalized and occurs as a logical subject, i.e., as an argument of a predicate. Third, classes as many, unlike sets, are pluralities, i.e., plural objects that are literally made up of their members so that a class as many of more than one member, i.e., a group, cannot itself be a member of a class as many. ${ }^{27}$ Membership in a class

\footnotetext{
${ }^{26}$ We do not take object variables to be individual variables if the latter are understood to have only (single) individuals in the ontological sense as values. Plural objects, or pluralities, which are not (single) individuals in the ontological sense, will also be values of object variables in the ontology we are now introducing.

${ }^{27}$ See [PoM], chapter VI, for Russell's discussion and adoption of this notion of a class.
} 
as many is defined as follows:

$$
x \in y{ }_{d f}(\exists A)[y=A \wedge(\exists z A)(x=z)] .
$$

That is, an object $x$ is a member of (a class as many) $y$ if, and only if, $y$ is the extension of a nominal concept $A$ and $x$ is an $A .^{28}$ From this it follows that where $A$ is name variable or constant,

$$
x \in A \leftrightarrow(\exists z A)(x=z) .
$$

In other words, to be one among the $A$ is to be (identical with) an $A$, where the first occurrence of ' $A$ ' is a nominalized occurrence and the second is as part of a quantifier phrase.

In order to deal with the nominalization of a complex name, such as 'per-

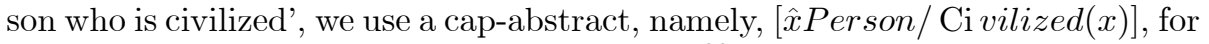
both the common name and its nominalization. ${ }^{29}$ Thus, $[\hat{x}$ Person/ Ci vilized $(x)]$, when nominalized, i.e., when it occurs as an argument of a predicate (such as the two-place membership predicate $\epsilon$ ) is understood to denote the class as many of persons who are civilized. If there is only one person who is civilized, then the class as many is just that one person; but if there are two or more persons who are civilized, then the class as many is taken to be that group of persons as a plurality, or what we also call a plural object. In this way the notion of a class as many as the extension of a name, proper or common, covers both the case when there is just one thing in that extension as well as when there are two or more things in the extension. The notion of a group is defined in this logic as follows:

$$
G r p={ }_{d f}[\hat{x} /(\exists y)(y \subset x)]
$$

where $\subset$ stands for proper inclusion, i.e., inclusion but with one or more things in the containing class not in the included class. ${ }^{30}$ That is, by definition, it is a theorem of the logic that every group has at least two members:

$$
(\forall x G r p)(\exists y / y \in x)(\exists z / z \in x)(y \neq z) .
$$

\footnotetext{
${ }^{28}$ The value of $y$ is a class as many because every value of the object variables is a class as many, whether it be a single object (individual) or a plural object, i.e., a plurality.

${ }^{29}$ See Cocchiarella [LCM] for a detailed description of the notation and development of the logic of classes as many. It should be noted that this logic is similar to, but not the same as, mereology. In particular, whereas

$$
(\forall x)(\forall y)[x O y \rightarrow(\exists z)(\forall u)(u O z \leftrightarrow u O x \vee u O y)]
$$

is a theorem of mereology, it is not a theorem of the logic of classes as many if the overlap relation, $x O y$, is taken to be the intersection of $x$ and $y$.

${ }^{30}$ Given the definition of inclusion simpliciter,

$$
y \subseteq x=_{d f}(\forall z)(z \in y \rightarrow z \in x),
$$

proper inclusion is defined as follows:

$$
y \subset x=_{d f} y \subseteq x \wedge x \nsubseteq y .
$$

Again, as we note beloe, the object variables here are not "individual" variables in the sense of having only single individuals as values. The values are classes as many, which include single objects (individuals in the ontological sense) and plural objects, i.e., pluralities.
} 
Note that because a class as many with just one member is identical with that one member, then everything, i.e., every object as a value of the bound object variables, is a class as many - though of course not every object is a plural object, i.e., a group, which, ontologically, is not the same as an individual. For convenience, following Nelson Goodman, we call things that are ontologically individual, i.e., things that are not groups, atoms, meaning by this only that they are the urelements of classes as many. That is,

$$
\text { Atom }=_{d f}[\hat{x} / \square \neg(\exists y)(y \subset x)],
$$

where the ' $\square$ ' for necessity indicates that not having a proper subclass is necessary to being an atom, i.e., it is a feature that atoms always have in every possible world. ${ }^{31}$ It follows, of course, that it is impossible for an atom to be a group, i.e.,

$$
\text { Atom }=[\hat{x} / \neg \diamond(\exists y G r p)(x=y)] .
$$

This is a modal version of the notion of an atom as used by Nelson Goodman in his characterization of how nominalism understands individuals as opposed to pluralities or classes as many with more than one member. That is, an atom according to Goodman, is simply an element of the system that contains no other element of the system as a member. ${ }^{32}$ This does not mean that an atom is ontologically simple, or that we think of conceptual realism as a form of nominalism. In fact, we count all concreta among the atoms of conceptual realism, including all physical objects and events of whatever complexity, as well as all abstracta of the intensional order represented in the logic through the process of nominalization, i.e., all of the properties and relations(-in-intension) that are the "object-ified" intensional contents of our predicable and referential concepts, as well as all of the propositions that are the "object-ified" intensional contents of our speech and mental acts. All that the notion of atomicity does in this framework is distinguish those objects, or classes as many, that can be said to have an individuality, from those classes as many that are genuine pluralities, namely the classes as many that are groups as defined above. In this framework, the notion of an object is the same as that of a class as many, and includes both plural and individual objects, whereas the ontological notion of an individual is the same as that of an atom.

The notion of atom that is at issue here is not what is represented by the syntactic category of so-called terms, i.e., expressions that can be properly substituted for object variables and occur in formulas as arguments of predicates. It is not the case, in other words, that all of the entities that are represented by bound object variables and terms are individuals in the ontological sense, i.e., they are not all atoms. Rather, some of them are pluralities, or what we are calling groups. Ontologically, what the category of terms and object (or

\footnotetext{
${ }^{31}$ The interpretation of $\square$ may be no more than the necessity of tense logic - namely, always being the case - if there are no modal operators other than the tense operators. If there are no modal or tense operators at all, then $\square$ can be deleted or read as 'it is the case that'.

${ }^{32}$ See Goodman [WoI], p. 18. If we restrict ourselves to extensional languages, then the modal notion of an atom is understood to be just the extensional notion intended by Goodman.
} 
so-called "individual") variables represents are classes as many, some of which are atoms, and hence individuals in the ontological sense, and the remaining of which are groups or pluralities.

It is noteworthy in this regard that although the proper inclusion relation is defined in terms of membership, it is in terms of the relation of proper inclusion (as a relation between classes as many), and not of membership, that the notions of being an atom and of being a group are defined. In other words, it is proper inclusion that is generating pluralities; and proper inclusion fulfills Goodman's ontological criterion for what is nominalistically acceptable as a generating relation, namely, that a class as many is not an atom if, and only if, some class as many is properly included in it. ${ }^{33}$ The "nominalistic dictum", according to Goodman, is that "no two distinct things can have the same atoms" (op. cit., p. 21); that is,

$$
(\forall x)(\forall y)[(\forall z \text { Atom })(z \in x \leftrightarrow z \in y) \rightarrow x=y]
$$

This dictum is validated in our logic of classes as many, and in fact it is a consequence of the so-called axiom of extensionality ${ }^{34}$,

$$
(\forall x)(\forall y)[(\forall z)(z \in x \leftrightarrow z \in y) \rightarrow x=y]
$$

and the fact that only atoms can belong to a class as many, i.e.,

$$
(\forall x)(\forall y)[x \in y \rightarrow(\exists z \text { Atom })(x=z)] .
$$

Having an axiom of extensionality does not mean that nominal concepts that have the same extension at one time in one possible world necessarily have the same extension at all times in every possible world. This is because we restrict the unqualified form of Leibniz's law to atoms; i.e., instead of

$$
x=y \rightarrow(\varphi \leftrightarrow \psi),
$$

where $\psi$ is obtained from $\varphi$ by replacing one or more free occurrences of $x$ by free occurrences of $y$, we take

$$
(\exists z \operatorname{Atom})(x=z) \wedge(\exists z \text { Atom })(y=z) \rightarrow[x=y \rightarrow(\varphi \leftrightarrow \psi)]
$$

\footnotetext{
${ }^{33}$ See Goodman, op. cit., p. 21 , where what it means for a relation $R$ to be a generating relation is that for all $x, x$ is not an atom with respect to $R$ if, and only if, there is a $y$ such that $y R x$.

${ }^{34}$ For reasons having to do with possible conflicts with Leibniz's law in tense and modal contexts, we did not take extensionality as an axiom of the system described in [LCM]. Instead, we assumed the somewhat weaker rule:

$$
\text { If } \vdash(\forall z)(z \in x \leftrightarrow z \in y) \text {, then } \vdash x=y .
$$

We did note there, however, the possibility of assuming the axiom of extensionality and modifying Leibniz's law so as to restrict its application when applied to groups, which is the position we now adopt and think is preferable. Groups, it should be emphasized, do not have different members at different times. Rather it is nominal concepts that might have different groups as their extensions at different times.
} 
as an axiom schema of our framework. The unrestricted form is then assumed to hold only for extensional contexts. This is an important feature of our logic that distinguishes the individuality of atoms from the plurality of groups. Indeed, unlike atoms, or individuals in the ontological sense, the identity of groups, or pluralities essentially means only that they have the same members, which does justify the full, unrestricted form of Leibniz's law.

One important theorem schema of the logic of classes as many is the following:

$$
(\exists y)(y=[\hat{x} / \varphi x]) \leftrightarrow(\exists x) \varphi x \wedge(\forall x / \varphi x)(\exists z \text { Atom })(x=z),
$$

which says that the class as many of things that satisfy $\varphi$ "exists" (in the sense of being a value of the bound object variables) if, and only, something satisfies $\varphi$ and whatever satisfies $\varphi$ is an atom. Accordingly, where $\varphi x$ is the impossible condition of not being self-identical, $(x \neq x)$, it follows from this theorem schema that there can be no empty class as many, which is the first fundamental feature of classes as many indicated by Russell. That is, where the empty class as many, $\Lambda$, is defined as follows,

$$
\Lambda={ }_{d f}[\hat{x} /(x \neq x)],
$$

then a theorem of the logic is:

$$
\neg(\exists x)(x=\Lambda),
$$

as well as

$$
\neg(\exists x)(x \in \Lambda) .
$$

Another theorem of the logic is the thesis that every atom is identical with its singleton, which is the second fundamental feature of classes as many indicated by Russell:

$$
(\forall x)((\exists z \text { Atom })(x=z) \rightarrow x=[\hat{y} /(y=x)]) .
$$

This means, of course, that every atom is both a class as many and a member of itself:

$$
(\forall x \text { Atom })(x \in x),
$$

and, moreover, that whatever is a member of an atom as a class as many is identical with that atom:

$$
(\forall x A t o m)(\forall y)(y \in x \rightarrow y=x) .
$$

In regard to the third fundamental feature of classes as many, we note that because only atoms are members of classes as many, then groups, or plural objects, are not members of anything:

$$
(\forall x)[(\exists y G r p)(x=y) \rightarrow \neg(\exists z)(x \in z)]
$$

Finally, it noteworthy that because names, proper or common, can be nominalized and occur as terms, i.e., as arguments of predicates, another theorem of the logic is that if $A$ is a proper (or unshared) name of an atom, then $(\exists x A$ tom $)[(x=A) \wedge(\forall y A)(y=x)]$ is true, and therefore so is $F(A) \leftrightarrow$ 
$(\exists x A) F(x)$, for any predicable concept $F$, and hence so is $F(A) \leftrightarrow(\exists x)[x=$ $A \wedge F(x)$, which is the way this situation is represented in standard free logic. In other words, proper names of atoms, when occurring as arguments of predicates, function in the logic of classes as many exactly as they do in so-called standard free logic, and this is true even of proper names that only purport to name an atom, i.e., an individual, but are really vacuous. Instead of being basic or primitive, the free logic treatment of proper names of individuals (atoms) is derived and grounded in our wider conceptualist framework of nominalized names, proper or common.

\section{Groups and the Truth Conditions of Plural Reference}

One way in which the notion of a group is important is its use in determining the truth conditions of sentences that are irreducibly plural, i.e., sentences not logically equivalent to sentences that can be expressed without a plural reference to a group or plural predication about a group. An example of such a sentence is the so-called Geach-Kaplan sentence, 'Some critics admire only each other'.

Let us note that the plural reference in this sentence is really plural, and in particular that reference is being made to a group and not just to a class as many, which might consist of just one member. A single critic who admires no one would in effect be a class as many of critics having exactly one member, and every member of this class would vacuously satisfies the condition that he admires only other members the class. But it is counter-intuitive to claim that the sentence 'Some critics admire only each other' could be true only because there is a critic who admires no one. Rather, the sentence is true if, and only if, there is a group of critics every member of which admires only other members of the group. This can be formulated in our conceptualist logic as follows:

$$
(\exists x G r p / x \subseteq[\hat{y} C r i t i c])(\forall y / y \in x)(\forall z)[\operatorname{Admire}(y, z) \rightarrow z \in x \wedge z \neq y] .
$$

Another example of an irreducibly plural reference is 'Some people are playing cards', where by 'some people' we do not mean that at least one person is playing cards, but that a group of people are playing cards, and that they are doing it together and not separately. The truth conditions of this sentence can be represented accordingly as follows:

$$
(\exists x G r p / x \subseteq[\hat{y} \text { Person }]) \text { Playing-Cards }(x),
$$

where the argument of the predicate is irreducibly plural. ${ }^{35}$ Of course, in saying that a group of people are playing cards we mean that the members of the

\footnotetext{
${ }^{35}$ Note that although the verb phrase 'is playing cards' is singular when applied to an individual (atom), it is plural when applied to a group; i.e., we can say that the group is playing cards as well as that the members of the group are playing cards, where it is the same event or situation that is being described. This is similar to the "grammatical difficulty" noted by Russell that "[a] collection, grammatically, is singular, whereas $A$ and $B, A$ and $B$ and $C$, etc. are essentially plural" ([PoM], p. 69].
} 
group are playing cards (together), and hence that the members of the group are playing cards with every other member of the group. That is,

$$
(\forall x G r p / x \subseteq[\hat{y} \text { Person }])[\text { Playing-Cards }(x) \rightarrow(\forall y / y \in x) \text { Playing-Cards }(y)]
$$

and

$$
\begin{aligned}
(\forall x G r p / x & \subseteq[\hat{y} \text { Person }])[\text { Playing-Cards }(x) \rightarrow \\
& \rightarrow(\forall y / y \in x)(\forall z / z \in x / z \neq y) \text { Playing-Cards-with }(y, z)]
\end{aligned}
$$

are understood as consequences of what is meant by saying that a group is playing cards. ${ }^{36}$ The converse, however, does not follow in either case. That is, we could have every member of a group playing cards without the group playing cards together, and we could even have every member playing cards with every other member in separate games without all of them playing cards together in a single game.

A similar analysis applies to 'John and Mary are playing cards', where the plural subject 'John and Mary' is taken as referring to the group consisting of John and Mary - just as Russell maintained in [PoM] regarding 'and' as a combination of terms. ${ }^{37}$ That is, the truth conditions of this sentence can be represented as:

$$
\left(\exists_{1} x \operatorname{Grp} / x=[\hat{y} /(y=\text { John } \vee y=\text { Mary })]\right) \text { Playing-Cards }(x) .
$$

To be sure, given the symmetry of 'playing-cards-with', it might be argued that this sentence has the same truth conditions as 'John is playing cards with Mary, and Mary is playing cards with John', which is not plural at all, no less irreducibly so. But then we need only consider a sentence like 'John, Mary, and Joan are playing cards' to have a sentence that is irreducibly plural. This sentence does imply the separate sentences 'John is playing cards with Mary', 'John is playing cards with Joan', 'Mary is playing cards with John', 'Mary is playing cards with Joan', etc., which are not plural, but the converse implication does not hold in this case. That is, John may be playing two games of cards simultaneously, one with Mary and the other with Joan, so that 'John is playing cards with Mary and John is playing cards with Joan' is true without it also being true that John, Mary and Joan are playing cards together. There are some kinds of activities between individuals, in other words, that are irreducibly plural.

Another type of example is plural identity, as in:

Russell and Whitehead are the coauthors of PM.

Here, reference is to the group consisting of Russell and Whitehead, and what is predicated of this group is that it is identical with the group consisting of those

\footnotetext{
${ }^{36}$ In this example, we understand the preposition 'with' to be a predicate modifier that adds one new argument position to the predicate being modified. Thus, applying this modifier to ' $x$ is playing cards' we get ' $x$ is playing cards with $y$ '.

${ }^{37}$ We assume here and throughout that John and Mary - and later Joan as well-are not identical and that their names are being used with existential presupposition.
} 
who coauthored PM. Rephrasing the complex common name 'co-author of PM' as '(thing) who coauthored PM', let us use ' $\Rightarrow$ ' for the relation between an English expression and its logical analysis or symbolization. Then, the analysis of the plural definite description can be given as follows ${ }^{38}$ :

the coauthors of $\mathrm{PM} \stackrel{(}{\Rightarrow}\left(\exists_{1} y \operatorname{Grp} / y=[\hat{z} /\right.$ Coauthored $\left.(z, P M)]\right)$.

Then, using ' $A$ ' and ' $B$ ' for 'Russell' and 'Whitehead', the plural identity sentence can now be symbolized as ${ }^{39}$

$$
\left(\exists_{1} x G r p / x=\left[\hat{z} /(z=A \vee z=B)\left(\exists_{1} y G r p / y=[\hat{z} / \text { Coauthored }(z, P M)]\right)(x=y) .\right.\right.
$$

A similar analysis applies to the sentence

The triangles that have equal sides are the triangles that have equal angles.

That is, where ' $A$ ' is a name constant for 'triangle' and ' $F$ ' and ' $G$ ' are one-place predicates for 'has equal sides' and 'has equal angles', respectively, then the two plural definite descriptions can be represented as:

The triangles that have equal sides $\doteq\left(\exists_{1} x G r p / x=[\hat{z} A / F(z)]\right)$,

The triangles that have equal angles $\stackrel{\Rightarrow}{=}\left(\exists_{1} y G r p / y=[\hat{z} A / G(x)]\right)$, and the plural identity sentence can be symbolized as:

$$
\left(\exists_{1} x G r p / x=[\hat{z} A / F(z)]\right)\left(\exists_{1} y G r p / y=[\hat{z} A / G(x)]\right)(x=y) .
$$

We should note, however, that given the axiom of extensionality, this sentence is provably equivalent to

A triangle has equal sides if, and only if, it has equal angles.

which can be symbolized as:

$$
(\forall x A)[F(x) \leftrightarrow G(x)] .
$$

\footnotetext{
${ }^{38}$ The very tentative approach we adopt here to common names based on a relation, such as ' $x$ is a coauthor of $y$ ' is to treat it as 'thing $x$ who coauthored $y$ ', or perhaps, using the closest superordinate the context allows, as 'person $x$ who coauthored $y$ '.

An alternative is take ' $x$ is a coauthor of $y$ ' as ' $x$ a coauthor who coauthored $y$ ', and similarly ' $x$ is a parent of $y$ ' as ' $x$ is a parent who is a parent of $y$ ', etc. Admittedly, neither approach for common names based on a relation is as satisfactory as one would like .

${ }^{39} \mathrm{As}$ an assertion, reference is made in this case only to Russell and Whitehead, and the definite description 'the authors of PM' is deactivated, so that the cognitive structure of the assertion is represented as

$$
\left(\exists_{1} x \operatorname{Grp} / x=\left[\hat{z} /(z=A \vee z=B)\left[\lambda x I S\left(x,\left[\exists_{1} y \operatorname{Grp} / y=[\hat{z} \text { Author } / \operatorname{Wrote}(z, P M)]\right]\right)\right](x) .\right.\right.
$$

But because the copula $I s$ in this formula is extensional in it second-argument position, this formula is equivalent to what we display above. For convenience, we ignore representing deactivations in this paper when they occur in an extensional context.
} 
That is, strictly speaking, the truth conditions of this sentence does not irreducibly involve plural reference to a group (or groups).

Another type of example is the predication of cardinal numbers, as in Russell's example, 'Brown and Jones are two of Miss Smith's suitors'. In this example, as Russell emphasizes, "it is Brown and Jones who are two, and this is not true of each separately". What the sentence describes, according to Russell, is a situation that is "characteristic of classes [as many]", which in this case is of Brown and Jones taken collectively, and not "of Brown and Jones severally", i.e., distributively $([\mathrm{PoM}]$, p. 57$)$. Indeed, it is in the predication of cardinal numbers that we find Russell proclaiming "the fundamental doctrine upon which all rests," i.e., "the doctrine that the subject of a proposition may be plural, and that such plural subjects are what is meant by classes [as many] which have more than one term" (ibid., p. 517), which is what we mean here by a group. It is this doctrine that is fundamental to our understanding of the natural numbers, as when we say that the Apostles are twelve, meaning that as a plurality the group of Apostles has twelve members, not that each Apostle is twelve. Here, the plural definite description, 'the Apostles' is understood to refer to the Apostles as a group, which means that we can symbolize the description as follows:

$$
\text { The Apostles } \Rightarrow\left(\exists_{1} x G r p / x=[\hat{x} \text { Apostle }]\right) .
$$

Of course, the verb phrase ' $x$ has twelve members' can be symbolized as a complex predicate as follows,

$$
x \text { has twelve members } \rightleftharpoons\left[\lambda x\left(\exists^{12} y\right)(y \in x)\right](x),
$$

where, as is well-known, the numerical quantifier $\exists^{12}$ is definable in first-order logic with identity. ${ }^{40}$ Note that this is really a plural predicate, i.e., it can be truthfully applied only to a plurality, namely a class as many, or group, with twelve members. The whole sentence can then be symbolized as follows:

$$
\left(\exists_{1} x G r p / x=[\hat{x} \text { Apostle }]\right)\left[\lambda x\left(\exists^{12} y\right)(y \in x)\right](x),
$$

or, by $\lambda$-conversion, more simply as

$$
\left(\exists_{1} x G r p / x=[\hat{x} \text { Apostle }]\right)\left(\exists^{12} y\right)(y \in x)
$$

Here, again, we have a clear example of Russell's doctrine of how the subject of a sentence can be plural, and that the plurality, or plural object, referred to by such a subject is a class as many with more than one member.

One might object, perhaps, to the use of paraphrase in replacing 'The Apostles are twelve' by 'The group of Apostles has twelve members'. The objection

\footnotetext{
${ }^{40}$ Strictly speaking, the quantifier ${ }^{\prime} \exists^{12}$, is deactivated when it occurs in the predicate of an assertion. That is, the predicate is then represented by $\left[\lambda x\left(\left[\exists^{12} y\right] \in x\right)\right]$. Note, however, given the extensionality of $\in$,$$
\left[\lambda x\left(\exists^{12} y\right)(y \in x)\right]=\left[\lambda x\left(\left[\exists^{12} y\right] \in x\right)\right]
$$

is provable.
} 
is not that the noun phrase 'The Apostles' does not purport to refer to the group of Apostles; rather, the objection is that we need to account for the logical connection between 'The Apostles are twelve' and 'The group of Apostles has twelve members', and, in particular, we need to explain the source of the plural 'are' in 'The Apostles are twelve'.

It is clear, as already noted above, that the plural verb phrase 'are twelve' is not the plural form of the singular verb phrase 'is twelve', the way the phrase 'are Apostles' is the plural of 'is an Apostle', and hence that its source cannot be explained as a simple pluralization of the verb. The explanation that we will propose in the next section depends on the claim that the most basic way in which we speak and think about different numbers of things is in our use of numerical quantifier phrases, as when we say that there are twelve Apostles. The point we want to note here is that this statement can be grammatically analyzed as

$$
[\text { twelve Apostles }]_{N P}[\text { there are }]_{V P} \text {, }
$$

where the noun phrase 'twelve Apostles' is taken as the subject of the sentence, and 'there are', which is the plural of 'there is', is taken as the verb phrase. It is our contention that the source of the plural 'are' in 'The Apostles are twelve' is the 'are' in 'There are twelve Apostles', which we paraphrased as 'The group of Apostles has twelve members'. The question that we will return to later is how do we logically analyze the plural predicate 'there are' and connect the three different sentences, 'There are twelve Apostles', 'The group of Apostles has twelve members', and 'The Apostles are twelve'.

\section{The Cognitive Structure of Plural Reference}

Russell, we have noted, explained the difference between 'All men are mortal' and 'Every man is mortal' in terms of the denoting concepts expressed by their respective quantifier phrases; that is, he assumed that the denoting concept expressed by 'All men' is different form the denoting concept expressed by 'Every man'. This is plausible because 'All men' is the logical dual of 'Some men', which we use when we want to refer to a group of men and not just to one man - as in 'Some men carried the piano downstairs', which is irreducibly plural. Indeed, reading the 'some men' in this sentence as 'at least one man' - and, as a result, leaving it open whether more than one man was involved - is not correct when in fact we mean to refer to a group of men. The quantifier phrase 'every man' is the logical dual of 'some man', when the latter is understood as meaning 'at least one man'. It is not the logical dual of 'some men' when we intend to refer to a group of men.

This distinction between reference to a group of men as opposed to reference to some man, meaning at least one, as in 'Some man broke the bank at Monte Carlo', is essential in a framework based on the pragmatics of speech and mental acts, and it should not be eliminated for the sake of logical convenience. The question is how can we develop this difference in a logically coherent way, and in 
particular in a way that is based on the logical forms that represent the cognitive structure of our speech and mental acts.

What we propose is to represent plural common names and plural monadic predicates by an operator that when applied to a name results in the plural form of the name, and similarly when applied to a monadic predicate results in the plural form of that predicate. We will use the letter ' $P$ ' as the symbol for this plural operator and we will represent its application to a name $A$ or predicate $F$ by placing the letter ' $P$ ' as a superscript of the name or predicate, as in $A^{P}$ and $F^{P}$. Thus, we extend the simultaneous inductive definition of the meaningful (well-formed) expressions of our conceptualist framework to include the following clauses:

1. if $A$ is a name variable or constant, then $A^{P}$ is a plural name variable or constant; respectively;

2. if $A$ is a name, $x$ is an object variable, and $\varphi x$ is a formula, then $[\hat{x} A / \varphi x]^{P}$ and $[\hat{x} / \varphi x]^{P}$ are plural names;

3. if $A / \varphi(x)$ is a (complex) name, then $(A / \varphi(x))^{P}=A^{P} /[\lambda x \varphi(x)]^{P}(x)$ and $[\hat{x} A / \varphi(x)]^{P}=\left[\hat{x} A^{P} /[\lambda x \varphi(x)]^{P}(x)\right]$;

4. if $F$ is a one-place predicate variable or constant, or of the form $[\lambda x \varphi(x)]$, then $F^{P}$ is a one-place plural predicate;

5. if $A^{P}$ is a plural name, $x$ is an object variable, and $\varphi$ is a formula, then $\left(\forall x A^{P}\right) \varphi$ and $\left(\exists x A^{P}\right) \varphi$ are formulas.

In regard to clause (5), we read, e.g., ' $\left(\forall x M a n^{P}\right)$ ' as the plural phrase 'all men' and ' $\left(\exists x \operatorname{Man}^{P}\right)$ ' as the plural phrase 'some men', and similarly ' $\left(\forall x \operatorname{Dog}^{P}\right)$ ' as 'all dogs' and ' $\left(\exists x \operatorname{Dog}^{P}\right)$ ' as 'some dogs', etc. We note that a plural name is not a name simpliciter and that unlike the latter there is no rule for the nominalization of plural names. This is because a nominalized name (occurring as an argument of a predicate) can already be read as plural if its extension is plural, and we do not want to confuse and identify a name simpliciter with its plural form.

Also, only monadic predicates are pluralized. A two-place relation $R$ can be pluralized in either its first- or second-argument position, or even both, by using a $\lambda$-abstract, as with $[\lambda x R(x, y)]^{P},[\lambda y R(x, y)]^{P},\left[\lambda x\left[\lambda y[R(x, y)]^{P}(y)\right](x)\right]^{P}$, respectively; and a similar observation applies to $n$-place predicates for $n>2$. Thus, for example, we can represent an assertion of 'Some people are playing cards with John' by pluralizing the first-argument position of the two-place predicate ' $x$ is playing cards with $y$ ' as follows:

$$
\left(\exists x \text { Person }^{P}\right)[\lambda x \text { Playing-Cards-with }(x, J o h n)]^{P}(x) .
$$

Semantically, of course, we understand the plural reference in this assertion to be to a group of people, a fact that is made explicit by assuming the following as a meaning postulate for all (nonplural) names $A$ whether simple or complex:

$$
\left(\exists x A^{P}\right) \varphi(x) \leftrightarrow(\exists x G r p / x \subseteq[\hat{y} A]) \varphi(x) .
$$


Of course, if a group of people are playing cards with John, then it follows that each person is playing cards with John, though, as already noted, the converse does not also hold. The one-direction implication from the plural to the singular can be described by assuming the following as part of the way that the predicate modifier 'with' operates ${ }^{41}$ :

$$
\begin{aligned}
& (\forall x)\left([\lambda x \text { Playing-Cards-with }(x, \text { John })]^{P}(x) \rightarrow\right. \\
\rightarrow & (\forall y / y \in x)[\lambda x \text { Playing-Cards-with }(x, \text { John })](y)) .
\end{aligned}
$$

Similarly, where $F$ is one-place predicate constant for ' $x$ carries the piano downstairs', then 'Some men carry the piano downstairs' can be symbolized as

$$
\left(\exists x \operatorname{Man}^{P}\right) F^{P}(x),
$$

which, by (MP1), means that some group of men carry the piano downstairs, and hence that some group of men is such that every man in the group carries the piano downstairs with the other men in the group. Given that the plural definite description, 'the men in $x$ other than $z$ ', can be symbolized as follows,

$$
\text { the men in } x \text { other than } z \doteq\left(\exists_{1} y(\operatorname{Man} /(y \in x \wedge y \neq z))^{P}\right) \text {, }
$$

then that there is a group of men such every man in the group carries the piano downstairs with the other men in the group can be represented as follows:

$(\exists x G r p / x \subseteq[\hat{y} M a n])(\forall z / z \in x)\left(\exists_{1} y(\operatorname{Man} /(y \in x \wedge y \neq z))^{P}\right)[\lambda y F-w i t h(z, y)]^{P}(y)$,

which, by (MP1), reduces to

$(\exists x G r p / x \subseteq[\hat{y} M a n])(\forall z / z \in x)\left(\exists_{1} y G r p / y=[\hat{y} M a n / y \in x \wedge y \neq z]\right)[\lambda y F \text {-with }(z, y)]^{P}(y)$,

where the relation ' $z$ carries the piano downstairs with $y$ ' is taken as plural in its second-argument position.

Now given the logical duality of $\left(\forall x A^{P}\right)$ with $\left(\exists x A^{P}\right)$, the way $(\forall x)$ is dual to $(\exists x)$, the postulate for universal plural reference is then as follows:

$$
\left(\forall x A^{P}\right) \varphi(x) \leftrightarrow(\forall x G r p / x \subseteq[\hat{y} A]) \varphi(x) .
$$

Thus, because we can represent the cognitive structure of an assertion of 'All men are mortal' as,

$$
\left(\forall x \operatorname{Man}^{P}\right) \operatorname{Mortal}^{P}(x) .
$$

then, semantically, by (MP2), that assertion amounts to predicating mortality to every group of men,

$$
(\forall x G r p / x \subseteq[\hat{y} M a n]) \operatorname{Mortal}^{P}(x),
$$

\footnotetext{
${ }^{41}$ Note that because everything is a class as many, this condition applies even when $x$ is an atom. In that case, of course, the condition is redundant.
} 
which is equivalent to saying without existential presupposition that the members of the entire group of men taken collectively are mortal:

$$
(\forall x G r p / x=[\hat{y} M a n]) \operatorname{Mortal}^{P}(x) .
$$

This last, given that the class as many of men is in fact a group-i.e., has more than one member - is in conceptualist terms essentially what Russell claims in $[\mathrm{PoM}]$, namely, that the denoting phrase "All men' in the sentence 'All men are mortal' denotes the class as many of men.

Let us note also that the plural verb phrase 'are mortal' is semantically reducible; that is, mortality can be predicated of a group if, and only if, every member of the group is mortal. In other words, as part of the meaning of the predicate 'mortal' we have the following as a meaning postulate:

$$
\operatorname{Mortal}^{P}(x) \leftrightarrow(\forall y / y \in x) \operatorname{Mortal}(y) .
$$

We can now see why it is that 'Every man is mortal' implies 'All men are mortal', whereas the converse does not also hold; for whereas 'All men are mortal' is vacuously true when there is just one man, and hence no group of men, 'Every man is mortal' is not in that case also vacuously true and would in fact be false if that one man were not mortal. ${ }^{42}$

In general, in other words, the logical equivalence between 'Every $A$ is $F$ ' and 'All $A^{P}$ are $F^{P}$, where $A$ is a nonplural common name and $F$ is a nonplural monadic predicate is provable on condition that the class as many of $A$ is a group, i.e., that there are at least two $A$ 's:

$$
\vdash(\exists y G r p)([\hat{x} A]=y) \rightarrow\left[(\forall x A) F(x) \leftrightarrow\left(\forall x A^{P}\right) F^{P}(x)\right] .
$$

Now it would be convenient if every plural predicate were reducible to its singular form the way that $\operatorname{Mortal}^{P}$ is, but that is not the case, as we noted above in regard to the predicate $[\lambda x \text { Playing-Cards-with }(x, J o h n)]^{P}$, which is taken as plural with respect to its first-argument position, and also the complex predicate for carrying the piano downstairs with the other members of a group. Another example of this sort is the sentence 'Some politicians campaign against each other'. Here, by 'to campaign against each other' we understand a verb phrase that applies to a group only if every member of that group campaigns against every other member of the group. ${ }^{43}$ We can symbolize the sentence accordingly as follows:

$$
\left(\exists x \text { Politician }^{P}\right)[\lambda x(\forall y / y \in x)(\forall z / z \in x / z \neq y) \text { Campaign-against }(y, z)](x)
$$

which, by (MP1), reduces to

$$
(\exists x G r p / x \subseteq[\hat{y} \text { Politician }])(\forall y / y \in x)(\forall z / z \in x / z \neq y) \text { Campaign-against }(y, z) .
$$

\footnotetext{
${ }^{42} \mathrm{~A}$ more perspicuous example is the falsity of 'Every moon of the Earth is made of green cheese' as compared with the vacuous truth, on our analysis, of 'All moons of the Earth are made of green cheese'.

${ }^{43}$ We also have the somewhat different irreducibly plural sentence, 'Some politicians campaign only against each other', which is similar to our earlier example of 'Some critics admire only each other'.
} 
It is clear of course that we can go on with many other examples of sentences that are irreducibly plural, such as 'Some students met at a restaurant and shared a pizza' and 'Some lawyers who are partners are suing the tobacco industry', etc.

There are other kinds of plural assertions whose cognitive structure we need to formally represent as well. In particular, there are assertions expressed by sentences such as 'Rogers and Hammerstein wrote musicals' and 'Mary and Joan are playing cards with John', etc. These involve the kinds of plural subjects that Russell had in mind when he introduced his 'and'-operator, which was to be applied to terms and result in a complex term - and which, semantically, denoted a group, i.e., a class as many of more than one member. ${ }^{44}$ The question is how are we to represent these kinds of plural references, especially in conceptualism where referential concepts are represented by determiner-quantifier phrases? Our proposal is that we add conjunctive quantifier phrases to our logical grammar.

Now if we add conjunctive quantifier phrases to our logic, we can represent the cognitive structure of an assertion of 'Rogers and Hammerstein wrote musicals' and 'Mary and Joan are playing cards with John' as follows, where, for convenience, we use $A$ and $B$ for 'Rogers' and 'Hammerstein', respectively,:

$$
(\exists x A \& \exists y B) \text { Wrote-Musicals }([\hat{z} /(z=x \vee z=y)]),
$$

and

$$
(\exists x \text { Mary \& } \exists \text { yoan })[\lambda z \text { Playing-Cards-with }(z, J o h n)]^{P}([\hat{z} /(z=x \vee z=y)]) .
$$

Here, the general proposal is that where $A$ and $B$ are proper names of different atoms - as we assume 'Mary', 'Joan', 'Rogers', and 'Hammerstein' are - and $F$ is a non-plural one-place predicate, then a sentence of the form ' $A$ and $B$ are $F^{P}$, can be symbolized as $(\exists x A \& \exists y B) F^{P}([\hat{z} /(z=x \vee z=y)])$. That is

$$
A \text { and } B \text { and are } F^{P} \doteq(\exists x A \& \exists y B) F^{P}([\hat{z} /(z=x \vee z=y)]) .
$$

In this way, by iterating the conjunctive quantifiers, we can represent Russell's so-called "combination of objects", as when we say that $A_{1}$ and $A_{2} \ldots$ and $A_{n}$ are $F^{P} \cdot{ }^{45}$

As part of this proposal, because, following Russell, we understand the plural conjunctive reference to $A$ and $B$ to be to the group consisting of $A$ and $B$, we assume the following as a meaning postulate as well:

$(\exists x A \& \exists y B) \varphi([\hat{z} /(z=x \vee z=y)]) \leftrightarrow\left(\exists_{1} u G r p / u=[\hat{z} /(z=A \vee z=B)] \varphi(u)\right.$

\footnotetext{
${ }^{44}$ See $[\mathrm{PoM}]$, p. 55 .

${ }^{45}$ This proposal can be generalized and applied to common names $A$ and $B$ as well by replacing ' $=$ ' by ' $\in$ ' and noting that in the case of proper names of atoms ' $(z \in x \vee z \in y)$ ' is provably equivalent with ' $(z=x \vee z=y)$ '. An example with common names is 'Dogs and sailors keep off the grass'. We can also allow for generalization to other quantifiers as well, but we will ignore those generalizations here.
} 
The above two formulas then reduce out accordingly to

$\left(\exists_{1} x G r p / x=[\hat{z} /(z=\right.$ Mary $\vee z=$ Joan $)][\lambda x \text { Playing-Cards-with }(x, \text { John })]^{P}(x)$

and

$$
\left(\exists_{1} x G r p / x=[\hat{z} /(z=A \vee z=B)] \text { Wrote-Musicals }(x) .\right.
$$

\section{Where Cardinal Numbers Come From}

Finally let us return to the question left unanswered at the end of the previous section, namely, how we are to analyze the quantifier phrase 'there are' when it functions as a plural predicate. Consider, as an example, the sentence, 'There are liberal republican senators', which, as noted in section one, we take to be synonymous with 'There are senators who are republican and liberal'. This sentence, let us note, is the plural form of 'There $i s$ a senator who is republican and liberal', which can be grammatically structured as,

[a senator who is republican and liberal $]_{N P}[\text { there is }]_{V P}$,

and the plural form of the sentence can be similarly grammatically structured as,

$$
[\text { senators who are republican and liberal }]_{N P}[\text { there are }]_{V P} \text {. }
$$

Now the logical analysis of the above singular noun phrase is,

a senator who is republican and liberal $\rightleftharpoons(\exists x$ Senator $/ \operatorname{Re} \operatorname{publican}(x) \wedge \operatorname{Liberal}(x))$, and the logical analysis of the singular verb phrase as a predicate is,

$$
\text { there is } \Rightarrow[\lambda x(\exists y)(x=y)]
$$

the infinitive of which can be read as 'to be an $x$ such that there is something $x$ is'. The singular form of the sentence can accordingly be formalized as:

$$
(\exists x \text { Senator } / \text { Re } \operatorname{publican}(x) \wedge \operatorname{Liberal}(x))[\lambda x(\exists y)(x=y)](x) .
$$

Now what we propose is that the logical form assigned to the plural form of the sentence should be derived from the singular form by having both the referential and the predicate expressions pluralized:

$$
(\exists x(\text { Senator } / \text { Re publican }(x) \wedge \text { Liberal }(x)))^{P}[\lambda x(\exists y)(x=y)]^{P}(x),
$$

which, by (MP1), gives us

$$
(\exists x G r p / x \subseteq[\hat{y} \text { Senator } / \operatorname{Re} \operatorname{publican}(y) \wedge \operatorname{Liberal}(y)])[\lambda x(\exists y)(x=y)]^{P}(x)
$$

as its semantic representation for the plural reference. In regard to the semantics of the plural predicate, we assume that a group has plural being in the sense of 'there are' if, and only if, each of its members has being in the sense of 'there 
is'. That is, the being of a plurality reduces to - i.e., is equivalent to - the being of each of the members of that plurality:

$$
(\forall x G r p)\left([\lambda x(\exists y)(x=y)]^{P}(x) \leftrightarrow(\forall z / z \in x)[\lambda x(\exists y)(x=y)](z)\right) .
$$

The right-hand side of this biconditional is logically true (and is a consequence of the free-logic axiom $(\forall z)(\exists y)(z=y))$, which means that the left-hand side of the biconditional is equivalent to ' $x=x$ '. This means that the above formula is equivalent to

$$
(\exists x G r p / x \subseteq[\hat{y} \text { Senator } / \text { Re publican }(y) \wedge \operatorname{Liberal}(y)])(x=x),
$$

and hence, by the exportation thesis for complex quantifier phrases and deletion of the redundant identity conjunct, ' $x=x$ ', equivalent to

$$
(\exists x \operatorname{Grp})(x \subseteq[\hat{y} \text { Senator } / \operatorname{Re} \operatorname{publican}(y) \wedge \operatorname{Liberal}(y)]) .
$$

In other words, the plural form of the sentence semantically amounts to saying that there is a group of senators who are republican and liberal, which, intuitively, is exactly what we understand the initial statement to say. Our general proposal is that other sentences with a plural 'there are' should be analyzed in a similar way, i.e., as being represented by the plural predicate $[\lambda x(\exists y)(x=y)]^{P}$.

In particular, to return to the question raised in the previous section, the sentence 'There are twelve Apostles', which we grammatically structured as

$$
[\text { twelve Apostles }]_{N P}[\text { there are }]_{V P} \text {, }
$$

can now be logically analyzed as

$$
\left(\exists^{12} x \text { Apostles }\right)[\lambda x(\exists y)(x=y)]^{P}(x),
$$

which, as noted above about the plural predicate, reduces to

$$
\left(\exists^{12} x \text { Apostle }\right)(x=x),
$$

as well as

$$
\left(\exists^{12} x\right)(\exists y \text { Apostle })(x=y),
$$

which says that twelve things are Apostles, which is another way of saying that there are twelve Apostles. ${ }^{46}$

Now as we suggested earlier the most basic way in which we speak and think about different numbers of things is in our use of numerical quantifier phrases, as when we say that there are two authors of PM, three people playing cards, twelve Apostles, etc. These quantifier phrases can be nominalized in conceptual realism the way that we earlier nominalized the phrase, 'a unicorn',

\footnotetext{
${ }^{46}$ The application of $\exists^{12}$ to the singular 'Apostle' is appropriate here because it says in effect that there are twelve individual Apostles, i.e., twelve individuals named by 'Apostle'. If we used the plural, 'Apostles ${ }^{P}$, , the result would amount to saying that there are twelve groups of Apostles, which is not what is intended.
} 
which means that they are first transformed into a (complex) predicate, which in turn is then nominalized and transformed into an abstract singular term, the denotatum of which is an intensional object. This kind of double transformation is what we described elsewhere as Frege's double-correlation thesis - except that Frege attached only the common name 'object' to his quantifiers and took other common names to be predicates. ${ }^{47}$ Frege, moreover, being an extensionalist, did not identify the objects correlated with his quantifiers as intensional objects, but as value-ranges (Wertverläufe). The general idea in any case is that where $\exists^{k}$ is a numerical quantifier, which when applied to a name $A$ is read as 'there are $k$ many $A^{\prime}$, the double-correlation thesis can be formulated as follows,

$$
(\exists F)(\forall A)(\forall G)\left[\left(\exists^{k} x A\right) G(x) \leftrightarrow F([\hat{x} A / G(x)])\right],
$$

where instead of a value-range as the argument of the concept $F$ corresponding to the numerical quantifier $\exists^{k}$ as Frege would have it, we have a class as many. In particular, taking the numerical quantifier $\exists^{12}$ for $\exists^{k}$, we have

$$
(\exists F)(\forall A)(\forall G)\left[\left(\exists^{12} x A\right) G(x) \leftrightarrow F([\hat{x} A / G(x)])\right] .
$$

Now, clearly the concept $F$ that is posited here as provably such that

for all name concepts $A$ and all predicable concepts $G$, there are twelve $A$ that are $G$ if, and only if, the group of $A$ that are $G$ falls under $F$

is none other than the predicable concept of having twelve members, which we symbolized earlier as $\left[\lambda x\left(\exists^{12} y\right)(y \in x)\right]$. In other words, by the above doublecorrelation thesis we have

$$
(\forall A)(\forall G)\left[\left(\exists^{12} x A\right) G(x) \leftrightarrow\left[\lambda x\left(\exists^{12} y\right)(y \in x)\right]([\hat{x} A / G(x)])\right],
$$

from which, by substituting 'Apostle' for ' $A$ ' and ' $x=x$ ' for ' $G(x)$ ', and applying $\lambda$-conversion, we have

$$
\left(\exists^{12} x \text { Apostle }\right)(x=x) \leftrightarrow\left(\exists^{12} y\right)(y \in[\hat{x} \text { Apostle } /(x=x)]),
$$

and therefore by canceling the redundant identity in $[\hat{x} \operatorname{Apostle} /(x=x)]$,

$$
\left(\exists^{12} x \text { Apostle }\right)(x=x) \leftrightarrow\left(\exists^{12} y\right)(y \in[\hat{x} \text { Apostle }]) .
$$

But, as noted above, the left-hand side of this biconditional is equivalent to our formulation of 'There are twelve Apostles', namely, $\left(\exists^{12} x\right.$ Apostle $)[\lambda x(\exists y)(x=$ $y)]^{P}(x)$, which means that the biconditional is equivalent to

$$
\left(\exists^{12} x \text { Apostle }\right)[\lambda x(\exists y)(x=y)]^{P}(x) \leftrightarrow\left(\exists^{12} y\right)(y \in[\hat{x} \text { Apostle }]) .
$$

\footnotetext{
${ }^{47}$ See Frege [GdA], vol. 1, section 25, and chapters two and four of Cocchiarella, [LSAP] for a discussion of this thesis
} 
But if there are twelve Apostles, then the definite description 'the group of Apostles', as symbolized by $\left(\exists_{1} y G r p / y=[\hat{x}\right.$ Apostle $\left.]\right)$, denotes the same group as is denoted by the abstract [ $\hat{x}$ Apostle], i.e.,

$$
\left(\exists_{1} z G r p / z=[\hat{x} \text { Apostle }]\right)(z=[\hat{x} \text { Apostle }])
$$

is true. From this identity and the last biconditional above it follows that the statement that there are twelve Apostles is logically equivalent to the statement that the group of Apostles has twelve members, i.e.,

$$
\left(\exists^{12} x \text { Apostle }\right)[\lambda x(\exists y)(x=y)]^{P}(x) \leftrightarrow\left(\exists_{1} z G r p / z=[\hat{x} \text { Apostle }]\right)\left(\exists^{12} y\right)(y \in z)
$$

is provable, which is one of the logical connections we wanted to establish.

Finally, let us note that the predicable concept that we predicate in 'The Apostles are twelve' can be identified with the concept of having twelve members, a concept that every group with twelve members falls under. That is, as a predicable concept, we can define each cardinal number $K$ to be the predicable concept that those groups that have $k$ many members fall under, and then the cardinal number $k$ itself can be identified with the "object-ified" correlate of the concept $K$. In other words, starting with the quantifier notion expressed by 'There are $k$ many $A$ ', we obtain the predicable concept $K$ under which a group falls if, and only if, it has $k$ many members, and then, by "object-ifying", or "nominalizing", the predicable concept $K$, we obtain the number $k$ as the abstract object correlated with the concept. It is in this way, by going through referential and predicable concepts and the process of nominalization, that we are able to grasp and understand the role of numbers as abstract objects.

In particular, the predicable concept 12 can now be defined as the concept under which an object falls if, and only if, that object is a group having twelve members:

$$
12=\left[\lambda y(\exists A)\left(y=A \wedge\left(\exists^{12} x A\right)(x \in y)\right)\right] .
$$

The number 12 is then the object correlated with this predicable concept. Thus, we are able, in this way, to we give a logical ground for paraphrasing 'The Apostles are twelve' as 'The group of Apostles has twelve members'. That is, we can now be symbolize 'The Apostles are twelve' as

$$
\left(\exists_{1} \text { xApostles }^{P}\right) 12(x),
$$

which, by (MP1) reduces to

$$
\left(\exists_{1} x G r p / x=[\hat{y} \text { Apostle }]\right) 12(x),
$$

which, by definition, $\lambda$-conversion and identity logic, reduces to

$$
\left(\exists_{1} x G r p / x=[\hat{y} \text { Apostle }]\right)\left[\lambda x\left(\exists^{12} y\right)(y \in x)\right](x) .
$$

Thus, the three sentences, 'The Apostles are twelve', 'The group of Apostles has twelve members', and 'There are twelve Apostles' are each seen to be logically equivalent to one another. Each, moreover, is provably equivalent to the 
following simplest version of all:

$$
12([\hat{x} \text { Apostle }]) .
$$

\section{Concluding Remarks}

Russell's early theory of denoting concepts and classes as many can be reconstructed and developed in a framework of conceptual realism, which is an alternative to Russell's own early framework of logical realism. Just as denoting concepts are what quantifier phrases express in Russell's early theory, referential concepts are what quantifier phrases stand for in conceptualism, where by a referential concept we mean a type of cognitive capacity that informs our speech and mental acts with a referential nature and accounts for the intentionality, or directedness, of those acts. A logic of classes as many as the extensions of both proper and common names can be developed in this framework and used to account for the truth conditions of plural reference and predication. Among classes as many we distinguish those that are atoms, i.e., those that have one member and are identical with that one member, from groups, i.e., those that have more than one member, which are only pluralities of objects. The atoms, which can be abstract as well as concrete objects, are the only true ontological individuals of the framework, whereas groups are simply pluralities of atoms satisfying Nelson Goodman's nominalistic constraints and the being, or existence, of which is reducible to that of their members. Groups, more importantly, are the basis of a semantics for plural reference and predication.

The connection between referential concepts and groups, or classes as many, is a theory of names that encompasses both proper and common names, and among the latter complex as well as simple common names. Names, proper or common, and simple or complex, occur as parts of the quantifier phrases that stand for referential concepts. But, like predicates, names can also be nominalized and occur as terms, i.e., as arguments of predicates and substituends of object variables; and when they occur as terms they denote classes as many, if they denote at all, where a class as many of one object is identical with that one object, and where there is no empty class as many. In this way, proper names of individuals can function as logical subjects just the way they do in so-called free logic, i.e., in a logic free of existential presuppositions regarding singular terms. Leśniewski's ontology, which is also called a logic of names can be completely interpreted within this conceptualist framework, and the well-known oddities of Leśniewski's system are shown not to be odd at all when his logic is interpreted in this way.

\section{References}

[LSAP] Cocchiarella, Nino B., Logical Studies in Early Analytic Philosophy, Ohio State University Press, Columbus, 1987. 
[CRLF] Cocchiarella, Nino B., "Conceptual Realism as a Theory of Logical Form," Revue Internationale de Philosophie 2/1997, n 200 (1997): 175199.

[RCR] Cocchiarella, Nino B., "Reference in Conceptual Realism," Synthese 114 (1998): 169-202.

[LRML] Cocchiarella, Nino B., "A Logical Reconstruction of Medieval Terminist Logic in Conceptual Realism," Logical Analysis and History of Philosophy 4 (2001): 35-72.

[CILO] Cocchiarella, Nino B., "A Conceptualist Interpretation of Leśniewski's Ontology", History and Philosophy of Logic, 22 (2001): 29-43.

[LCM] Cocchiarella, Nino B., "On the Logic of Classes as Many", in Studia Logica 70 (2002): 303-338.

[GdA] Frege, G., Die Grundgesetze der Arithmetik, vols. 1 \& 2, Hildesheim, 1962.

[R\&G] Geach, Peter T., Reference and Generality, 3rd ed., Ithaca and London, Cornell Univ. Press, 1980.

[WoI] Goodman, Nelson, "A World of Individuals", in The Problem of Universals, Notre Dame, University of Notre Dame Press, 1956.

[LO] Lewjeski, C., "On Leśniewski's Ontology", Ratio 1 (1958): 150-176.

[SQLQ] Küng G., and T. Canty, "Substitutional Quantification and Leśniewskian Quantifiers," Theoria, 36 (1979): 165-182.

[PTQ] Montague, Richard M., "The Proper Treatment of Quantification in Ordinary English," in Formal Philosophy, Selected Papers of Richard Montague, ed., R.H. Thomason, New Haven, Yale Univ. Press, 1974.

[RR] Quine, W.V., The Roots of Reference, La Salle, IL., Open Court,1973.

[SLL] Rickey, V.F., "A Survey of Leśniewski's Logic," Studia Logica, 36 (1977): 407-426).

[PoM] Russell, Bertrand, The Principles of Mathematics, 2nd ed., N.Y., Norton \& Co.., 1938.

[OD] Russell, Bertrand, "On Denoting", Mind, 1905, reprinted in Logic and Knowledge, edited by R.C. Marsh, London, George Allen \& Unwin Ltd., 1956.

[1908] Russell, Bertrand, "Mathematical Logic as Based on the Theory of Types," American Journal of Mathematics 1908, reprinted in Essays in Analysis by Bertrand Russell, edited by D. Lackey, N.Y., Braziller, 1973. 
[PM] Russell, Bertrand, and Whitehead, Alfred N., Principia Mathematica, vol.1, London, Cambridge Univ. Press,1910. (Vols. 2 and 3 were published in 1912 and 1913.)

[LC] Slupecki, J., "S. Leśniewski's Calculus of Names," Studia Logica, vol. III (1955): 7-72.

[G\&E] Sellars, Wilfrid F., "Grammar and Existence: A Preface to Ontology," in Science, Perception and Reality, London, Routledge \& Kegan Paul, 1963. 